\title{
DEVELOPING THEORY THROUGH SIMULATION METHODS
}

\author{
JASON P. DAVIS \\ KATHLEEN M. EISENHARDT \\ Stanford University \\ CHRISTOPHER B. BINGHAM \\ University of Maryland
}

\begin{abstract}
We describe when and how to use simulation methods in theory development. We develop a roadmap that describes theory development using simulation and position simulation in the "sweet spot" between theory-creating methods, such as multiple case inductive studies and formal modeling, and theory-testing methods. Simulation strengths include internal validity and facility with longitudinal, nonlinear, and process phenomena. Simulation's primary value occurs in creative experimentation to produce novel theory. We conclude with evaluation guidelines.
\end{abstract}

Simulation is an increasingly significant methodological approach to theory development in the literature focused on strategy and organizations (e.g., Adner, 2002; Lant \& Mezias, 1990; Repenning, 2002; Rivkin \& Siggelkow, 2003; Zott, 2003), Indeed, several influential research efforts (e.g., Cohen, March, \& Olsen, 1972; March, 1991) have used simulation as their primary method. Yet while simulation has become an important methodology, its value for theory development remains clouded and even controversial.

On the one hand, some argue that simulation methods contribute effectively to theory development. For example, simulation can provide superior insight into complex theoretical relationships among constructs, especially when challenging empirical data limitations exist (Zott, 2003). It can also provide an analytically precise means of specifying the assumptions and theoretical logic that lie at the heart of verbal theories (Carroll \& Harrison, 1998; Kreps, 1990). In addition, simulation can clearly reveal the outcomes of the interactions among multiple underlying organizational and strategic processes, especially as they unfold over time (Re-

We appreciate helpful conversations with Ron Adner, Peter Glynn, Ashish Goel, Riitta Katila, Bruce Kogut, Nelson Repenning, Jan Rivkin, and Jesper Sorenson; the suggestions of our anonymous reviewers; and the support of the Stanford Technology Ventures Program and the National Science Foundation (IOC Award \#0323176). penning, 2002). From these perspectives, simulation can be a powerful method for sharply specifying and extending extant theory in useful ways.

On the other hand, some researchers maintain that simulation methods often yield very little in terms of actual theory development. They suggest that simulations are simply "toy models" of actual phenomena, in that they either replicate the obvious or strip away so much realism that they are simply too inaccurate to yield valid theoretical insights (Chattoe, 1998; Fine \& Elsbach, 2000). For example, simulation research is usually based on at least some clearly unrealistic assumptions, such as zero search costs (Rivkin, 2000) and all strategic rules are effective (Davis, Eisenhardt, \& Bingham, 2007). In addition, simulation constructs are often "measured" by empirically distant approaches, such as "0" and " 1 " bit strings as representations of organizations (Bruderer \& Singh, 1996) and strategies (Rivkin, 2001). The results of research using simulation methods can also be dynamically indeterminate and overly complex (Fichman, 1999). From these perspectives, the value of simulation methods for theoretical development is tenuous.

The controversy surrounding the value of simulation methods for theory development partially arises, in our view, from a lack of clarity about the method and its related link to theory development. There appears to be limited understanding within the broad research commu- 
nity about (1) when simulation is a useful methodological choice for theory development, (2) how to select among the various simulation approaches (e.g., system dynamics versus genetic algorithms), (3) the appropriate steps for performing simulation research, and (4) the relevant criteria for evaluating simulation research. Most significant, there seems to be limited recognition within the research community of how simulation methods fit into the broader scheme of relating methodological choices to theoretical development.

Our purpose is to address these issues by clarifying when and how to use simulation methods in theory development. Although scholars writing about theory development (e.g., Dubin, 1976; Pfeffer, 1982; Priem \& Butler, 2001; Sutton \& Staw, 1995; Whetten, 1989) may have different emphases, most agree that theory has four elements: constructs, propositions that link those constructs together, logical arguments that explain the underlying theoretical rationale for the propositions, and assumptions that define the scope or boundary conditions of the theory. Consistent with these views, we define theory as consisting of constructs linked together by propositions that have an underlying, coherent logic and related assumptions.

Broadly, we attempt to make two contributions. First, we offer a roadmap for how to use simulation methods to develop theory. This roadmap synthesizes prior work on the design of simulation research (e.g., Sterman, 2000) and extends that work into specific areas, such as identifying appropriate research questions, choosing among simulation approaches, developing computational representations, elaborating the fundamental role of verification versus experimentation, and evaluating simulation research. We rely on exemplars from the extant literature to ground our observations. The intended result is a more complete roadmap for executing and evaluating theory development research using simulation methods than has previously existed. This roadmap is summarized in Table 1.

Second, we position simulation methodology within the broad context of theoretical development in the organizations and strategy literature. Relying on the related theory development literature (e.g., Priem \& Butler, 2001; Sutton \& Staw, 1995; Weick, 1989), we explore the rationale for using simulation, its relationship to other methods such as laboratory experiments, simulation's strengths and weaknesses, and guidelines for evaluating theoretical development using simulation. We argue that simulation is especially useful in the "sweet spot" between theory-creating research using such methods as inductive multiple case studies (Eisenhardt, 1989) and formal modeling (Freese, 1980), and theory-testing research using multivariate, statistical analysis (Pfeffer, 1993). That is, simulation enables the elaboration of rough, basic (or what we term simple) theory that is often derived from inductive cases or formal modeling into logically precise and comprehensive theory. This theory can then be effectively examined further using deductive logic and empirical evidence. Simulation is particularly useful when the theoretical focus is longitudinal, nonlinear, or processual, or when empirical data are challenging to obtain.

We begin by discussing the background of simulation methods. We then turn to the basic steps of conducting simulation research, including selecting research questions, choosing a computational approach, and developing experiments. We conclude with a discussion of the strengths and weaknesses of simulation research and guidelines for its evaluation.

\section{BACKGROUND}

We define simulation as a method for using computer software to model the operation of "realworld" processes, systems, or events (Law \& Kelton, 1991). This definition is consistent with other definitions that describe simulation models as virtual experiments (Carley, 2001) or as simplified pictures of the world having some, but not all, of the characteristics of that world (Lave \& March, 1975). In particular, simulation involves creating a computational representation of the underlying theoretical logic that links constructs together within these simplified worlds. These representations are then coded into software that is run repeatedly under varying experimental conditions (e.g., alternative assumptions, varied construct values) in order to obtain results.

While simulation can be used purely for description or exploration, ${ }^{l}$ our focus is on using

\footnotetext{
${ }^{1}$ There are a number of uses of simulation, including description of complicated systems, such as telecommuni-
} 
TABLE 1

Roadmap for Developing Theory Using Simulation Methods

\begin{tabular}{|c|c|c|}
\hline Step & Āctivities & Rationale \\
\hline Begin with a research question & $\begin{array}{l}\text { - Determine a theoretically intriguing } \\
\text { research question } \\
\text { - Look for a basic tension like structure } \\
\text { versus chaos, long versus short run }\end{array}$ & $\begin{array}{l}\text { Focuses efforts on a theoretically } \\
\text { relevant issue for which } \\
\text { simulation is especially effective }\end{array}$ \\
\hline Identify simple theory & $\begin{array}{l}\text { - Select simple theory that addresses } \\
\text { the research question } \\
\text { - Look for intertwined processes (e.g., } \\
\text { competition and legitimation), } \\
\text { nonlinearities, and longitudinal } \\
\text { effects } \\
\text { - Look for theory that requires data } \\
\text { that are challenging to obtain }\end{array}$ & $\begin{array}{l}\text { - Forms basis of computational } \\
\text { representation by giving shape to } \\
\text { theoretical logic, propositions, } \\
\text { constructs, and assumptions } \\
\text { - Focuses efforts on theoretical } \\
\text { development for which simulation } \\
\text { is especially effective }\end{array}$ \\
\hline Choose a simulation approach & $\begin{array}{l}\text { - Choose simulation approach that fits } \\
\text { with research question, assumptions, } \\
\text { and theoretical logic } \\
\text { - If the research does not fit an } \\
\text { approach or if the approach requires } \\
\text { extensive modification, choose } \\
\text { stochastic processes }\end{array}$ & $\begin{array}{l}\text { Ensures that the research uses an } \\
\text { appropriate simulation approach } \\
\text { given the research at hand }\end{array}$ \\
\hline $\begin{array}{l}\text { Create computational } \\
\text { representation }\end{array}$ & $\begin{array}{l}\text { - Operationalize theoretical constructs } \\
\text { - Build computational algorithm that } \\
\text { mirrors theoretical logic } \\
\text { - Specify assumptions } \\
\text { - Ensure that computational } \\
\text { representation allows theoretically } \\
\text { valuable experimentation }\end{array}$ & $\begin{array}{l}\text { - Embodies theory in software } \\
\text { - Provides construct validity } \\
\text { - Improves internal validity by } \\
\text { requiring precise constructs, logic, } \\
\text { and assumptions } \\
\text { - Sets the stage for theoretical } \\
\text { contributions }\end{array}$ \\
\hline $\begin{array}{l}\text { Verify computational } \\
\text { representation }\end{array}$ & $\begin{array}{l}\text { - Replicate propositions of simple } \\
\text { theory with simulation results } \\
\text { - Conduct robustness checks of } \\
\text { computational representation } \\
\text { - If verification fails, correct theory } \\
\text { and/or software coding }\end{array}$ & $\begin{array}{l}\text { - Confirms accuracy and robustness } \\
\text { of computational representation } \\
\text { - Confirms internal validity of the } \\
\text { theory }\end{array}$ \\
\hline $\begin{array}{l}\text { Experiment to build novel } \\
\text { theory }\end{array}$ & $\begin{array}{l}\text { Create experimental design (e.g., vary } \\
\text { construct values, unpack constructs, } \\
\text { alter assumptions, add new features) } \\
\text { based on likely theoretical } \\
\text { contribution and realism }\end{array}$ & $\begin{array}{l}\text { - Focuses experimentation on } \\
\text { theory development } \\
\text { - Builds new theory through } \\
\text { exploration, elaboration, and } \\
\text { extension of simple theory }\end{array}$ \\
\hline Validate with empirical data & $\begin{array}{l}\text { Compare simulation results with } \\
\text { empirical data }\end{array}$ & $\begin{array}{l}\text { Strengthens external validity of the } \\
\text { theory }\end{array}$ \\
\hline
\end{tabular}

simulation for theory development when simple theory exists (e.g., Rivkin, 2000; Rudolph \& Repenning, 2002). By simple theory, we mean undeveloped theory that has only a few constructs and related propositions with modest empirical

cation networks, and purely exploratory efforts, such as observing what emerges from simulating complex relationships. In contrast, our focus is specifically on using simulation for theory development when some simple theory exists. Its application ranges from incremental extensions of that theory to exploratory work that may rely on only a rough understanding of theoretical mechanisms. We appreciate the comments of an anonymous reviewer in clarifying this scope condition of our efforts and in suggesting language. or analytic grounding such that the propositions are in all likelihood correct but are currently limited by weak conceptualization of constructs, few propositions linking these constructs together, and/or rough underlying theoretical logic. Simple theory also includes basic processes that may be known (e.g., competition, imitation) but that have interactions that are only vaguely understood, if at all. Thus, simple theory contrasts with well-developed theory, such as institutional and transaction cost theories that have multiple and clearly defined theoretical constructs (e.g., normative structures, mimetic diffusion, asset specificity, uncertainty), 
well-established theoretical propositions that have received extensive empirical grounding, and well-elaborated theoretical logic. Simple theory also contrasts with situations where there is no real theoretical understanding of the phenomena.

Simulation is particularly suited to the development of simple theory because of its strengths in enhancing theoretical precision and related internal validity and in enabling theoretical elaboration and exploration through computational experimentation. In particular, simulation relies on some theoretical understanding of the focal phenomena in order to construct $\alpha$ computational representation. Yet simulation also depends on an incomplete theoretical understanding such that fresh theoretical insights are possible from the precision that simulation enforces and the experimentation that simulation enables.

In contrast, while it is possible to simulate well-developed theories, such as institutional and transaction cost theories, they offer fewer opportunities for new theoretical insights using the logical precision and experimentation of simulation. These theories are already wellelaborated. Thus, there is likely to be less payoff from simulation because it is likely just to replicate known theoretical ideas.

At the other end of the theory development spectrum are "clean-slate" theoretical situations. Here there is not much to simulate, and other methods such as multiple case induction and formal modeling are typically better methodological choices. In contrast with these extremes, simple theory has enough theoretical development to construct a computational representation, but also sufficient room to improve internal validity and to develop novel theoretical insights. In addition, simulation is especially useful for theory development when the focal phenomena involve multiple and interacting processes, time delays, or other nonlinear effects such as feedback loops and thresholds. In these situations, simulation is likely to reveal nonintuitive elaborations of simple theory that are difficult to uncover using other methods, including armchair thought processes.

Overall, a central value of simulation for theory development lies in the exploration, elaboration, and extension of simple theories. Theory development begins with one or several theoretical ideas (what we term simple theory) that are then represented in computer software, verified, and explored through computational experimentation. These experiments can range from incremental (e.g., adding a moderating relationship) to elaborate, involving numerous, wideranging experiments that push the theory well beyond its immediate application-for example, examining alternative theoretical logics (Lee, Mitchell, \& Sablynski, 1999). ${ }^{2}$ Several exemplar studies using simulation in theory development are listed in Table 2.

\section{ROADMAP FOR DEVELOPING THEORIES WITH SIMULATIONS}

\section{Begin with an Intriguing Research Question and Simple Theory}

Like all good research, studies that develop theory through simulation should begin with an intriguing research question that reflects deep understanding of the extant literature and relates to a substantial theoretical issue (Weick, 1989). Without such a question, simulation research simply becomes $\alpha$ "fishing expedition" in which the researcher lacks focus and theoretical relevance and risks becoming overwhelmed by computational complexity.

Research questions can originate from many sources. Sometimes they come from conundrums within basic science. March (1991), for example, relied on complexity theory from the biological and computer sciences to conceptualize a research question that examined the trade-off between the exploration of new possibilities and the exploitation of old certainties. Sometimes research questions are motivated by intriguing observations from inductive case study research. For example, Rudolph and Repenning (2002) used the counterintuitive observations from a case study describing the 1977 Tenerife airport disaster (Weick, 1993) as the inspiration for their research question asking how small problems can become major catastrophes. Sometimes research questions emerge from combining process theories, such as when Gavetti and Levinthal (2000) asked how cognition influences experiential learning. Research questions may also come from the classic tradi-

\footnotetext{
${ }^{2}$ We appreciate the comments of one of our anonymous reviewers in assisting us in highlighting this continuum and language.
} 
TABLE 2

Recent Examples of Simulation Research

\begin{tabular}{|c|c|c|c|c|}
\hline Study & Research Question & Key Processes & Approach & $\begin{array}{l}\text { Representative } \\
\text { Findings }\end{array}$ \\
\hline $\begin{array}{l}\text { Rudolph \& Repenning } \\
\text { (2002) }\end{array}$ & $\begin{array}{l}\text { When do small } \\
\text { interruptions } \\
\text { create major } \\
\text { catastrophes? }\end{array}$ & $\begin{array}{l}\text { Adaptation and } \\
\text { selection }\end{array}$ & $\begin{array}{l}\text { System } \\
\text { dynamics }\end{array}$ & $\begin{array}{l}\text { Variance in the rate of } \\
\text { interruptions affects } \\
\text { emergence of tipping } \\
\text { points }\end{array}$ \\
\hline Sastry (1997) & $\begin{array}{l}\text { How do } \\
\text { organizations } \\
\text { undergo } \\
\text { fundamental } \\
\text { change? }\end{array}$ & $\begin{array}{l}\text { Change and } \\
\text { inertia }\end{array}$ & $\begin{array}{l}\text { System } \\
\text { dynamics }\end{array}$ & $\begin{array}{l}\text { An additional negative } \\
\text { feedback loop } \\
\text { corrects theoretical } \\
\text { logic of punctuated } \\
\text { equilibrium theory }\end{array}$ \\
\hline Rivkin (2000) & $\begin{array}{l}\text { What is the optimal } \\
\text { strategic } \\
\text { complexity? }\end{array}$ & $\begin{array}{l}\text { Replication and } \\
\text { imitation }\end{array}$ & $\begin{array}{l}\text { NK fitness } \\
\text { landscape }\end{array}$ & $\begin{array}{l}\text { Moderate strategic } \\
\text { complexity is } \\
\text { optimal }\end{array}$ \\
\hline $\begin{array}{l}\text { Gavetti \& Levinthal } \\
\text { (2000) }\end{array}$ & $\begin{array}{l}\text { How does cognition } \\
\text { improve } \\
\text { experiential } \\
\text { learning? }\end{array}$ & $\begin{array}{l}\text { Experiential } \\
\text { learning and } \\
\text { cognition }\end{array}$ & $\begin{array}{l}\text { NK fitness } \\
\text { landcape }\end{array}$ & $\begin{array}{l}\text { Cognition is most } \\
\text { useful in improving } \\
\text { experiential learning } \\
\text { at moderate levels of } \\
\mathrm{K} \text { interactions }\end{array}$ \\
\hline Zott (2002) & $\begin{array}{l}\text { How does adaptive } \\
\text { learning occur } \\
\text { within } \\
\text { bargaining? }\end{array}$ & Adaptive learning & $\begin{array}{l}\text { Genetic } \\
\text { algorithm }\end{array}$ & $\begin{array}{l}\text { Adaptive failures may } \\
\text { occur even with } \\
\text { complete information }\end{array}$ \\
\hline $\begin{array}{l}\text { Bruderer \& Singh } \\
\quad \text { (1996) }\end{array}$ & $\begin{array}{l}\text { How does organiza- } \\
\text { tional learning } \\
\text { affect the } \\
\text { evolution of a } \\
\text { population of } \\
\text { organizations? }\end{array}$ & $\begin{array}{l}\text { Variation, } \\
\text { adaptation, and } \\
\text { selection }\end{array}$ & $\begin{array}{l}\text { Genetic } \\
\text { algorithm }\end{array}$ & $\begin{array}{l}\text { Environment } \\
\text { influences when } \\
\text { organizational } \\
\text { learning is most } \\
\text { useful for the } \\
\text { population's } \\
\text { convergence to an } \\
\text { optimal form }\end{array}$ \\
\hline Lomi \& Larsen (1996) & $\begin{array}{l}\text { How do competition } \\
\text { and legitimation } \\
\text { affect density } \\
\text { dependence? }\end{array}$ & $\begin{array}{l}\text { Competition and } \\
\text { legitimation }\end{array}$ & $\begin{array}{l}\text { Cellular } \\
\text { automata }\end{array}$ & $\begin{array}{l}\text { Neighborhood size } \\
\text { moderates the } \\
\text { relationship of } \\
\text { density with } \\
\text { founding and failure } \\
\text { rates }\end{array}$ \\
\hline March (1991) & $\begin{array}{l}\text { What is the } \\
\text { relationship } \\
\text { between } \\
\text { exploration and } \\
\text { exploitation? }\end{array}$ & $\begin{array}{l}\text { Exploitation and } \\
\text { exploration }\end{array}$ & $\begin{array}{l}\text { Stochastic } \\
\text { processes }\end{array}$ & $\begin{array}{l}\text { Exploitation processes } \\
\text { are effective in the } \\
\text { short run but } \\
\text { destructive in the } \\
\text { long run }\end{array}$ \\
\hline $\begin{array}{l}\text { Davis, Eisenhardt, \& } \\
\text { Bingham (2007) }\end{array}$ & $\begin{array}{l}\text { What is the optimal } \\
\text { degree of } \\
\text { structure? }\end{array}$ & Improvisation & $\begin{array}{l}\text { Stochastic } \\
\text { processes }\end{array}$ & $\begin{array}{l}\text { Unpredictability (not } \\
\text { ambiguity, } \\
\text { complexity, or } \\
\text { velocity) is the driver } \\
\text { of the tension } \\
\text { between structure } \\
\text { and chaos }\end{array}$ \\
\hline
\end{tabular}

tion extending formal analytic models (Adner, 2002).

While simulation shares an emphasis on intriguing and theoretically relevant research questions with other methods, simulation is particularly suited to the theoretical development of simple theory. As described earlier, simple theory is undeveloped theory that involves a few constructs and related propositions with some empirical or analytic grounding but that is limited by weak conceptualization, few propositions, and/or rough underlying theoretical logic. 
Simple theory may also include concepts and basic processes from well-known theories (e.g., competition, imitation), especially when the research focus is on their vaguely (if at all) understood interactions. Propositions may be formally stated (Davis et al., 2007; Rivkin, 2001) or implicit (Rudolph \& Repenning, 2002). The fundamental idea is that theory development using simulation should begin with a simple theory, rather than either an extensive theoretical base or $a$ clean theoretical slate. This simple theory should address a theoretically intriguing research question that focuses on a fundamental phenomenon. Such theory can then be a platform from which powerful theory can be developed through the verification and experimentation enabled by simulation (Lave \& March, 1975; Stinchcombe, 1968).

Rivkin (2001), for example, focused on a research question that asked, "What is the optimal level of strategic complexity?" He relied on a single proposition linking strategic complexity with performance that was based on case studies and prior theoretical work. This proposition stated that a moderate level of strategic complexity leads to the highest performance. Similarly, Rudolph and Repenning (2002) used previous case study research as the basis of a simple theory describing how minor events could create major catastrophes. The theory consisted of several propositions that linked quantity of interruptions, stress, and performance.

Simulation is particularly effective when the simple theory involves several basic processes, such as competition and legitimation (Lomi \& Larsen, 1996) or imitation and experimentation (Zott, 2003), with only vaguely (if at all) understood longitudinal interactions. These interactions are often difficult to study with traditional statistical methods or to anticipate with thought processes. In contrast, these processes usually can be computationally represented, verified, and then explored (separately and in interaction) using simulation. For example, Sastry (1997) investigated the longitudinal interaction between inertial and change processes. Her results included unexpected insights about timepacing and dynamic markets that were not anticipated in previous theory and in previous empirical evidence (Tushman \& Romanelli, 1985).

Simulation is also particularly effective for theory development when the research question involves a fundamental tension or trade-off. The tension may be temporal, such as short- versus long-run implications (Morch, 1991; Sterman, Repenning, \& Kofman, 1997); structural, such as too much structure versus too little (Davis et al., 2007; Rudolph \& Repenning, 2002); or spatial, such as near versus far away (Lomi \& Larson, 1996; Schelling, 1971). These tensions often result in nonlinear relationships, such as tipping point transitions and steep thresholds. These and other nonlinear relationships are difficult to discover using inductive case methods and difficult to explore with traditional statistical techniques. Yet they often offer surprising, nonintuitive results.

\section{Choose a Simulation Approach}

Assuming that simulation is the best way to proceed (e.g., intriguing research question and simple theory), the next step is to select a simulation approach. This choice should depend on the fit of the research question, assumptions, and the theoretical logic of the simple theory with those of the simulation approach. This choice is crucial because the simulation approach can impose a theoretical logic, type of research question, and related assumptions. Much as the choice of a statistical technique (e.g., OLS regression versus event history) can shape theory-testing empirical research, the choice of simulation approach shapes the subsequent results. In fact, the choice of simulation approach may be closer to choosing a theoretical framework (e.g., resource dependence versus transaction cost economics) because of its framing of research questions, key assumptions, and theoretical logic.

Several well-known simulation approaches have been used for theory development in the organizations and strategy literature. ${ }^{3}$ Some are common, such as system dynamics (Repenning, 2002; Rudolph \& Repenning, 2002) and NK fitness

\footnotetext{
${ }^{3}$ Other researchers (e.g., Dooley, 2002) have used simulation typologies. We chose our typology because it is a finegrained mapping that accurately relates to the major approaches that are used in the organizations and strategy literature. That is, it reflects the most frequently used categorization in the relevant extant research. Given the scope of our paper, our description of these approaches is necessarily limited. Interested readers should turn to technical treatments if they wish to use these approaches.
} 
landscapes (Levinthal, 1997; Rivkin \& Siggelkow, 2003). Others are less frequently used, such as genetic algorithms (Bruderer \& Singh, 1996) and cellular automata (Lomi \& Larsen, 1996). Each of these is a structured approach that constrains the theoretical logic, assumptions, and research questions that can be explored. In contrast, the stochastic process approach (Davis et al., 2007; March, 1991; Zott, 2003) is a customized approach that is useful when the structured approaches do not fit with the research at hand (see Table 3 for a comparison of these approaches).

System dynamics. The system dynamics approach focuses on how causal relationships among constructs can influence the behavior of a system (Forrester, 1961; Sastry, 1997; Sterman et al., 1997). The approach typically models a system (e.g., organization) as a series of simple processes with circular causality (e.g., variable $A$ influences voriable $B$, which influences vari- able A). These processes have some common constructs and so intersect in a set of circular causal loops. These causal loops can be positive such that feedback is self-reinforcing and amplifying, or negative such that feedback is dompening (Sterman, 2000). While each process may be well-understood, their interactions are often difficult to predict. The system typically includes stocks, acting as buffers (i.e., constructs with values that accumulate and dissipate over time, and so introduce time delays) and flows (i.e., constructs specifying temporal rates in the system).

Rudolf and Repenning (2002), for example, used system dynamics to examine why minor interruptions sometimes trigger sudden catastrophes within organizations. The authors used intersecting causal loops to model two different processes (one positive loop, one negative loop) by which stress, quantity of interruptions, and performance were causally related (Yerkes \&

TABLE 3

Comparison of Simulation Approaches

\begin{tabular}{|c|c|c|c|c|c|}
\hline Simulation Approach & Focus & $\begin{array}{l}\text { Common Research } \\
\text { Question(s) }\end{array}$ & Key Āssumptions & Theoretical Logic & Common Experiments \\
\hline \multicolumn{6}{|l|}{ System dynamics } \\
\hline $\begin{array}{l}\text { Sastry (1997), } \\
\text { Sterman, } \\
\text { Repenning, \& } \\
\text { Kofman (1997), } \\
\text { Repenning (20202), } \\
\text { Rudolph \& } \\
\text { Repenning (2002) }\end{array}$ & $\begin{array}{l}\text { Behavior of a system } \\
\text { with complex } \\
\text { causality and } \\
\text { timing }\end{array}$ & $\begin{array}{l}\text { What conditions create } \\
\text { system instability? }\end{array}$ & $\begin{array}{l}\text { - System of intersecting, circular } \\
\text { causal loops } \\
\text { - Stocks that accumulate and } \\
\text { dissipate over time } \\
\text { - Flows that specify rates within } \\
\text { system }\end{array}$ & $\begin{array}{l}\text { - Description } \\
\text { - Inputs to a system } \\
\text { of interconnected } \\
\text { causal loops, stocks, } \\
\text { and flows produce } \\
\text { system outcomes }\end{array}$ & $\begin{array}{l}\text { - Add causal loops } \\
\text { - Change mean of flow rates } \\
\text { - Change variance of flow } \\
\text { rates }\end{array}$ \\
\hline \multicolumn{6}{|l|}{ NK fitness landscapes } \\
\hline $\begin{array}{l}\text { Levinthal (1997), } \\
\text { Gavetti \& Levinthal } \\
\text { (2000), Rivkin (2000), } \\
\text { Rivkin \& Siggelkow } \\
\text { (2003) }\end{array}$ & $\begin{array}{l}\text { Speed and } \\
\text { effectiveness of } \\
\text { adaptation of } \\
\text { modular systems } \\
\text { with tight versus } \\
\text { loose coupling to } \\
\text { an optimal point }\end{array}$ & $\begin{array}{l}\text { - How long does it } \\
\text { take to find an } \\
\text { optimal point (e.g., } \\
\text { high-performing } \\
\text { strategy)? } \\
\text { - What is the } \\
\text { performance of the } \\
\text { optimal point? }\end{array}$ & $\begin{array}{l}\text { - System of N nodes, } \mathrm{K} \text { coupling } \\
\text { between nodes } \\
\text { - Fitness landscape that maps } \\
\text { performance of all combinations } \\
\text { - Adaptation via incremental } \\
\text { moves and long jumps }\end{array}$ & $\begin{array}{l}\text { - Optimization } \\
\text { - Adaptation of a } \\
\text { modular system } \\
\text { using search } \\
\text { strategies (i.e., long } \\
\text { jumps, incremental } \\
\text { moves) to find an } \\
\text { optimal point on a } \\
\text { fitness landscape }\end{array}$ & $\begin{array}{l}\text { - Vary N and K } \\
\text { - Change adaptation moves } \\
\text { Add a "map" of the } \\
\text { landscape } \\
\text { - Create an environmental jolt }\end{array}$ \\
\hline \multicolumn{6}{|l|}{ Genetic algorithms } \\
\hline $\begin{array}{l}\text { Bruderer \& Singh } \\
\text { (1996), Zott (2002) }\end{array}$ & $\begin{array}{l}\text { Adaptation of a } \\
\text { population of } \\
\text { agents (e.g., } \\
\text { organizations) via } \\
\text { simple learning } \\
\text { to an optimal } \\
\text { agent form }\end{array}$ & $\begin{array}{l}\text { - What affects the rate } \\
\text { of adaptation (or } \\
\text { learning or change)? } \\
\text { - When and/or does an } \\
\text { optimal form } \\
\text { emerge? }\end{array}$ & $\begin{array}{l}\text { - Population of agents with genes } \\
\text { - Evolutionary adaptation (v-s-r) } \\
\text { Variation via mutation } \\
\text { (mistakes) and crossover } \\
\text { (recombinations) } \\
\text { - Selection via fitness } \\
\text { (performance) } \\
\text { - Retention via copying selected } \\
\text { agents }\end{array}$ & $\begin{array}{l}\text { - Optimization } \\
\text { - Adaptation of a } \\
\text { population of } \\
\text { agents using an } \\
\text { evolutionary process } \\
\text { toward an optimal } \\
\text { agent form }\end{array}$ & $\begin{array}{l}\text { - Vary mutation probability } \\
\text { - Vary crossover probability } \\
\text { - Vary length of time of } \\
\text { evolution } \\
\text { - Create an environmental jolt }\end{array}$ \\
\hline \multicolumn{6}{|l|}{ Cellular automata } \\
\hline $\begin{array}{l}\text { Lomi \& Larsen } \\
\text { (1996) }\end{array}$ & $\begin{array}{l}\text { Emergence of macro } \\
\text { patterns from } \\
\text { micro interactions } \\
\text { via spatial } \\
\text { processes (e.g., } \\
\text { competition, } \\
\text { diffusion) in a } \\
\text { population of } \\
\text { agents }\end{array}$ & $\begin{array}{l}\text { - How does the pattern } \\
\text { emerge and change? } \\
\text { - How fast does a } \\
\text { pattern emerge? }\end{array}$ & $\begin{array}{l}\text { - Population of spatially arrayed } \\
\text { and semi-intelligent agents } \\
\text { - Agents use rules (local and } \\
\text { global) for interaction, some } \\
\text { based on spatial processes } \\
\text { - Neighborhood of agents where } \\
\text { local rules apply }\end{array}$ & $\begin{array}{l}\text { - Description } \\
\text { - Interactions among } \\
\text { agents following } \\
\text { rules produce } \\
\text { macrolevel patterns }\end{array}$ & $\begin{array}{l}\text { - Change the rules } \\
\text { - Change the neighborhood } \\
\text { size }\end{array}$ \\
\hline \multicolumn{6}{|l|}{ Stochastic processes } \\
\hline $\begin{array}{l}\text { March (1991), } \\
\text { Carroll \& Harrison } \\
\text { (1998), Zott (2003), } \\
\text { Davis, Eisenhardt, \& } \\
\text { Bingham (2007) }\end{array}$ & $\begin{array}{l}\text { Flexible approach to } \\
\text { a wide variety of } \\
\text { research } \\
\text { questions, } \\
\text { assumptions, and } \\
\text { theoretical logics }\end{array}$ & $\begin{array}{l}\text { No specific research } \\
\text { questions beyond } \\
\text { asking what the } \\
\text { effects of varying } \\
\text { the stochastic } \\
\text { sources are }\end{array}$ & $\begin{array}{l}\text { - One or more processes by which } \\
\text { system operates } \\
\text { - One or more stochastic sources } \\
\text { (e.g., process elements) } \\
\text { - Probablistic distributions for } \\
\text { each stochastic source }\end{array}$ & $\begin{array}{l}\text { No specific theoretical } \\
\text { logic }\end{array}$ & $\begin{array}{l}\text { - Change stochastic sources } \\
\text { - Vary levels of stochasticity } \\
\text { - Unpack constructs } \\
\text { - Change pieces of theoretical } \\
\text { logic }\end{array}$ \\
\hline
\end{tabular}


Dodson, 1908). The number of accumulated interruptions was included as a stock, and the rate of interruptions and the rate of their resolution were flows. By varying these rates, the authors were able to develop theory about when the system would be stable, when it would hit tipping points, and whether (and, if so, how fast) those tipping points would lead to catastrophe.

System dynamics is particularly applicable for understanding the behavior of systems with complex causality and timing. Research questions are often framed in terms of how specific initial conditions affect the stability of the system. That is, researchers are usually interested in finding the initial conditions that lead to abrupt, nonlinear changes, such as tipping points, catastrophes, and the emergence of vicious or virtuous cycles. Researchers often begin with two causal loops and then add successive ones in order to build intuition, understanding, and realism in a structured way. Although the approach can accommodate some stochasticity, it relies on deterministic differential equations and so is not as useful when there are many or complicated sources of stochasticity.

NK fitness landscapes. The NK approach was developed in evolutionary biology to study genetic systems (Kauffman, 1993). This approach focuses on how rapidly and effectively a modular system adapts to reach an optimal point, especially when interactions among the system components are crucial. Specifically, the system (e.g., organization, product, strategy) is conceptualized as a set of $\mathrm{N}$ nodes, and $\mathrm{K}$ interactions among the nodes. The system is assumed to use adaptation (sometimes termed search) strategies, such as incremental moves and long jumps, to find the optimal point (e.g., best organization, best product). To illustrate, Rivkin (2001) focused on strategy. He defined $\mathrm{N}$ as the elements of a strategy (e.g., manufacturing and advertising choices) and $\mathrm{K}$ as the degree of interaction among the elements. The optimal point was the highest performing strategy.

A key concept is the fitness landscape (Wright, 1931) that is created by assigning performance values (termed fitness) to every combination of values. The shape of the landscape depends on the interaction $(\mathrm{K})$ among the nodes (Kauffman, 1989). When there is little interaction (low K), there is one optimal combination (or perhaps a few). The corresponding fitness landscape is "smooth," with only one or a few hills such that it is easy to find the optimal point. As interaction (K) increases, more combinations become locally optimal. The corresponding fitness landscape is "rugged," with many hills of varying heights that correspond to varying performance levels. This landscape type is hard to traverse to find the optimal point (Kauffman, 1989). The overall theoretical logic of the NK approach emphasizes the adaptation of a modular system using specific search strategies to find an optimal point on a fitness landscape.

For example, Gavetti and Levinthal (2000) examined how experiential learning (alone and with cognition) affected the time needed to find an optimal policy for an organization. They represented organizational policy as $\mathrm{N}$ policy elements and $\mathrm{K}$ interactions among them. They then compared the time to find an optimal policy (and its performance) using only experiential learning (i.e., incremental moves) with using both experiential learning and cognition (i.e., a basic "map" of the landscape that enabled long jumps) under varying levels of coupling (K) among elements.

The NK approach is particularly applicable for understanding how the speed and effectiveness of adaptation to an optimum within a modular system are influenced by tight versus loose coupling among the system's components. Research questions are often framed as "problem solving" or "searching" to find an optimal point. Researchers often ask how long it takes to find an optimal point (e.g., high-performing strategy, high-performing product) or what the effectiveness or performance of the optimal point is (e.g., local versus global optimum). They are typically interested in how the number of nodes (e.g., number of product features), the interaction among nodes (e.g., tight versus loose coupling), types of adaptation (i.e., long jumps versus incremental moves), or the use of landscape "maps" (e.g., cognition, science) influences the time to find an optimal solution and/or the performance of that solution. Although the approach can be modified to accommodate some environmental dynamism (e.g., environmental jolts) or node intelligence, it is less useful when the effects of market dynamism, the intelligence and/or uniqueness of nodes in a modular system (e.g., differences among business units in an organization), or varied types of interaction (e.g., strong versus weak ties) are a central interest. 
Genetic algorithms. Like the NK approach, genetic algorithms are an optimization approach with roots in biology. But unlike the NK approach, genetic algorithms focus on how rapidly and effectively a population of heterogeneous agents composed of genes (e.g., population of organizations composed of routines, population of consumers with preferences) adaptively learns (Goldberg, 1989; Holland, 1975). ${ }^{4}$ Adaptation occurs through a stochastic evolutionary process (i.e., variation-selection-retention) that favors gradual improvement through accumulated experience (Aldrich, 1999; Hollond, 1975). Variations occur in two ways: mutation (i.e., random change of one or a few genes that corresponds to mistakes) and crossover (i.e., random switching of sets of genes among agents that corresponds to recombination of existing genes). Selection of agents (also termed genes) occurs according to their performance (also termed fitness) with respect to some metric. Retention (also termed reproduction) is the copying of the selected agents from one generation to the next. Over time, successful variations are more likely to be retained and form the basis of future variations (Andreoni \& Miller, 1995; Arifovic et al., 1997). Eventually, only high-performing agents remain in the population, and, ultimately, often only a single agent form survives (e.g., dominant design). The theoretical logic emphasizes the evolutionary adaptation of a population toward an optimal form that is path dependent and combinatorial.

For example, Bruderer and Singh (1996) used a genetic algorithm to examine organizational evolution within a population of organizations. In their model, each of the 250 organizations in the population was composed of 20 routines that could change as a result of both mutation and crossover variation processes. The authors were particularly interested in the effect of learning on organizational evolution. They found that

\footnotetext{
${ }^{4}$ Although there has been only limited use of genetic algorithms in the organizations and strategy literature we are focusing on, there is an emerging tradition in the economics literature. Applications include economic growth (e.g., Arifovic, Bullard, \& Duffy, 1997), auctions (e.g., Andreoni \& Miller, 1995), and forecasting (e.g., Bullard \& Duffy, 2001). This work is often framed in juxtaposition with highly rational models of agent behavior, such as game theoretic formulations. Readers with particular interest in genetic algorithms should consult these sources, as well as more general sources (e.g., Goldberg, 1989; Holland, 1975).
}

learning accelerated the discovery of an effective organizational form. Genetic algorithms can also be used to examine the evolution of specific types of strategies within an agent. For example, Zott (2002) used a genetic algorithm approach to model the bargaining behavior of a negotiator with private information. The genes were the negotiator's bargaining rules that determined when to offer a contract and when to accept or reject another's offer. Among other insights, the study clarified the effects of complete and incomplete information in producing inefficient (i.e., nonoptimal) outcomes, such as delays and failure to agree.

Genetic algorithms are particularly applicable for describing how heterogeneous agents (e.g., organizations, consumers) learn improved solutions (e.g., better organizational form, better strategy) through experimentation. As such, this approach is consistent with some important aspects of human learning, such as experiencebased action, importance of recent experience, creative synthesis of ideas, and occurrence of mistakes (Zott, 2002). Research questions are typically framed in terms of what affects the rate of adaptation (or sometimes learning or change) and whether a dominant form emerges. Researchers often experiment with rates and processes of mutation and crossover, as well as performance metrics. Although the approach can be modified, it is less useful when the value of the performance metrics varies (e.g., as in dynamic markets), the agents can engage in sophisticated cognitive processes that are not well-captured by experiential learning (e.g., foresight), or crossover is unlikely (e.g., technical standards limit reuse of product components across products in a population, internal labor markets limit mobility across organizations in a population).

Cellular automata. Although not widely used in the organizations and strategy literature, cellular automata have gained traction in the physical sciences as an approach that focuses on the emergence of macrolevel system patterns from microlevel interactions among spatially related and semi-intelligent agents (Wolfram, 2002). Cellular automata assume a system of agents that are spatially related (e.g., competitors in an industry, cities in a country). Spatial relatedness implies that the degree to which agents influence each other depends on the distance between them. The 
agents behave according to a few simple rules (i.e., semi-intelligent agents), some of which relate to how the agents influence each other (Langton, 1984). Typically, the rules relate to spatial processes such that nearby agents are influenced more than distant ones-for example, diffusion, propagation, and competition processes (Schelling, 1971). Although not required, the rules are usually uniform (i.e., all agents have the same rules) and deterministic (i.e., all rules are fixed). An important concept is the neighborhood that defines which agents are local (and so neighbors) and which are not. At least some rules designate behaviors taken in interaction with neighbors, but not with more distant agents.

For example, Lomi and Larsen (1996) used cellular automata to study density-dependence theory and the tension between competition and legitimation processes (Hannan \& Freeman, 1989). The organizations were spatially arrayed relative to one another in a two-dimensional grid. The organizations possessed rules for competition (affecting only those in the neighborhood) and legitimation (affecting all organizations). The authors then observed how the competitive and legitimating interactions among organizations (i.e., microlevel interactions) affected population density, founding rates, and failure rates (i.e., macrolevel patterns) over time.

Cellular automata are particularly useful for examining how macrolevel patterns emerge from spatial processes (e.g., diffusion, competition, propagation, and segregation) that operate at a micro level. In these processes, the behaviors of agents affect each other, but their influence diminishes with distance. Research questions usually ask how macrolevel patterns emerge and change. Researchers typically vary the size of the neighborhood, the relevant processes (e.g., diffusion, segregation) and their related rules, and the spatial array of agents (e.g., density of agents) in order to describe the emergence and change of macrolevel phenomena from microlevel interactions among agents. While cellular automata can be modified, the approach is less useful when intelligence resides at the system level (e.g., CEO in an organization of business units) or the interactions among agents are not spatially dependent.

Stochastic processes. Stochastic processes are a flexible approach that enables researchers to custom design their simulations (Gallager, 1996). ${ }^{5}$ The approach makes no particular assumptions about the system, research question, or theoretical logic. It is especially useful for exploring theories that do not fit with the theoretical logic and assumptions of the structured simulation approaches. For example, the environment may be dynamic (Davis et al., 2007; March, 1991), or the theoretical logic may involve temporal transmission processes (Carroll \& Harrison, 1998). Researchers typically piece together distinct processes that mirror the theoretical logic. They also build in several sources of stochasticity (e.g., environmental input, timing, elements of the process) and endow them with stochastic distributions that can be simple (e.g., 50/50 draw) or complex (e.g., normal and Poisson distributions). A key point is that while the simulation is custom designed and may have some original processes or constructs, researchers often use existing building blocks, such as known processes-for instance, Markov chains-and familiar sources of stochasticity and their related distributions - for instance, Poisson distribution for input arrival times (Law \& Kelton, 1991).

An example is research by Carroll and Harrison (1998). Building on their previous work (Harrison \& Carroll, 1991), these authors developed several underlying theoretical logics for the simple, well-known proposition positing that heterogeneity of tenure is related to heterogeneity of culture. These logics related to temporal transmission of culture and so did not fit with the theoretical logics of structured simulation approaches, such as system dynamics (circular causality) and NK (search for the optimal point). The authors custom designed their simulation by combining several processes, including turnover and socialization, and designating sources of stochasticity, such as the hiring and firing processes, and their related distributions.

Stochastic processes are particularly applicable when the research question, assumptions, or theoretical logic does not fit with a structured approach. Although it is sometimes possible to

\footnotetext{
${ }^{5}$ By stochastic processes, we mean a broad class of simulations that are unified by the use of custom-designed algorithms or combinations of algorithms. By contrast, although the structured simulation approaches may also often involve stochasticity, they have a much more specific structure.
} 
modify a structured approach to fit the research at hand, stochastic processes are the preferred approach when these modifications are extensive. Extensive modifications can become unwieldy, yielding a poor computational representation. When using stochastic processes, researchers typically ask how alternative theoretical logics, different assumptions, or varying sources of stochasticity affect system outcomes. They often hold some sources of stochasticity constant while varying others. The result is a flexible approach to theory development, albeit at the price of a lack of standardization and increased need for modeling ingenuity.

\section{Create the Computational Representation}

In the previous sections we described the importance of a theoretically intriguing research question, a simple theory that is likely to be accurate but incomplete, and an appropriate simulation approach (i.e., fits with the research question, assumptions, and theoretical logic). In this section we turn to computational representation of the theory. This activity is central to theory development using simulation. It involves (1) operationalizing the theoretical constructs, (2) building the algorithms that mirror the theoretical logic of the focal theory, and (3) specifying assumptions that bound the theory and results. Although we describe them separately, researchers usually engage in these activities interactively because constructs, algorithms, and assumptions are highly interdependent. Creating the computational representation is roughly analogous to the activities reported in the methods section of other types of research.

Operationalizing theoretical constructs concerns defining the computational measures for each construct (and, if not already done, creating its verbal definition). This is roughly analogous to creating empirical measures for theoretical constructs in other types of research. As described below, effective operationalization involves choosing an appropriate computational measure and range of values for each construct. It also involves using construct definitions and names that fit with the extant literature where possible (i.e., inventing new theoretical constructs only when none exists) in order to build reader intuition and confidence and to enhance the clarity of the theoretical contributions (Repenning, 2003).

One type of computational measure is a single measure (termed parameter) that has a range of possible values. For example, Davis and colleagues (2007) operationalized their ambiguity construct by defining a single computational measure with values ranging from 0 (no ambiguity) to 1 (complete ambiguity). For constructs with a range of values having no natural bounds (e.g., rates ranging from 0 to infinity), it is appropriate to artificially bound the range and then test these bounds to guard against the possibility that the values outside the bounds produce qualitatively different or contradictory results (Law \& Kelton, 1991). If so, the range of values should be adjusted.

A second type of computational measure is a multidimensional measure (often termed a bit string). Typically, it is effective to measure the most central constructs as bit strings (not parameters) because bit strings have more precision and dimensionality. These features enable more refined and better experimentation. An example of bit string representation is strategy as a set of ten decisions (Rivkin, 2000). In this type of representation, the dimensions of a construct are measured by specific values (often 0 and 1 and occasionally ? to indicate an absent value). For example, Bruderer and Singh (1996) operationalized organizational form as a bit string of twenty routines with $l$ indicating a correct routine, 0 indicating an incorrect one, and ? indicating an absent routine that could be learned.

A strength of simulation research is construct validity-that is, accurate specification and measurement of constructs (Cook \& Campbell, 1979). Simulation requires precise specification of constructs and their measures, and so avoids "noisy" measurement that affects construct validity in empirical research (Rosenthal \& Rosenow, 1991). In addition, as required by its rigorous, step-by-step logic, simulation involves precise specification of units of analysis (e.g., product, strategy) and intervening constructs that are often poorly conceptualized and unmeasured in empirical research. Since simulation eliminates the measurement errors associated with empirical data, convergent and discriminant validity are not germane (Campbell \& Fiske, 1959). Finally, simulation also has the advantage of quick, flexible adjustment of construct measures (and even the constructs them- 
selves) by changing the computer code. Such adjustment is usually challenging in empirical research, particularly after the data are collected.

The computational representation also involves building algorithms in software that captures the step-by-step theoretical logic underlying the simple theory. In other words, the software code should embody the theoretical logic. Specifically, the algorithms should consist of a series of steps for modifying construct values in accordance with the underlying theoretical logic of the simple theory. As noted earlier, structured simulation approaches (e.g., NK, genetic algorithms) offer a standardized approach for encoding theoretical logic that is useful when the research fits the simulation approach (Rivkin, 2001). In contrast, an unstructured approach such as stochastic processes offers flexibility when no structured approach fits the research.

Algorithmic representations vary in complexity. Some algorithms consist of two or three steps involving a few constructs (e.g., March, 1991; Rudolph \& Repenning, 2002). Others are multistep, involving several or more constructs (e.g., Carroll \& Harrison, 1998; Sterman et al., 1997). Algorithmic complexity should depend on the complexity of the underlying theoretical logic being represented and should relate to the well-known theoretical trade-off between parsimony and accuracy (Pfeffer, 1982). Like other methods, simulation research attempts to balance parsimony and accuracy by capturing the central logic while stripping away the nonessential. This balance is ultimately a judgment call. But, unlike other methods, it is often effective to err on the side of simplicity in simulation research in order to enhance the intuition and confidence of readers in the simulation results (Repenning, 2003). Complexity (and, thus, greater accuracy and realism) can then be added through a series of structured experiments.

Finally, computational representation involves specifying assumptions. Some of these assumptions relate to boundary or scope conditions of the theory. But other assumptions are simplifications of the simulation itself that enable the researcher to strip out complexity in order to focus on the central logic and constructs. Thus, these assumptions are intimately related to the complexity of the algorithmic rep- resentation. For example, both Rivkin's (2001) assumption of zero search costs and Adner's (2002) assumption that all markets are the same size enable less complicated algorithmic representations. As above, the key judgment is the balance between parsimony and accuracy. This is, of course, a familiar judgment in other research methods, where choices about sampling in specific contexts (e.g., single industry studies) or about using the controlled environment of the laboratory, in effect, enable a less complicated theoretical logic (Fine \& Elsbach, 2000). This judgment, however, is more readily changed in simulation research because of the relative ease of shifting computer code.

An important strength of theory development using simulation methods is internal validity (Campbell \& Stanley, 1966). Creating a computational representation involves the precise specification of the theoretical logic that is enforced through the discipline of algorithmic representation in software (Abelson, Sussman, \& Sussman, 1996). Coupled with the precise specification of constructs, measures, and assumptions that is also enforced by the software, the discipline of algorithmic representation sharpens loose theoretical arguments about the definition of constructs, relationships among constructs, and underlying logic (Carroll \& Harrison, 1998; Sastry, 1997). The result is theory that is more likely to exhibit strong internal validity.

\section{Verify the Computational Representation}

A critical step in developing theory using simulation methods is verification of the computational representation. Roughly analogous to manipulation checks in laboratory experiments and examination of correlation matrices in multivariate analysis, verification helps to ensure that the computational representation accurately embodies the theoretical logic, the theory is internally valid, and the simulation results con be interpreted with confidence.

Researchers should verify their computational representation in several ways. The most important is comparing simulation results with the (implicit or explicit) propositions of the simple theory. If the simulation confirms the propositions, then the theoretical logic and its compu- 
tational representation are likely to be correct. ${ }^{6}$ Rivkin (2001), for example, verified his computational representation by confirming his proposition that the advantage of a firm's replication of its own strategy over another firm's imitation of the same strategy was greatest at moderate levels of strategic complexity. He did so by running the simulation at various values of strategic complexity and then comparing the simulation results with his inverted U-shaped prediction. In simulations where the simple theory centers on several well-known processes, each process should be verified.

Simulation researchers should further verify their computational representation with robustness checks (sometimes termed sensitivity anal$y_{\text {sis }}{ }^{7}$ ) that increase confidence that the computational representation is stable. For example, Zott (2003) used alternative starting values of the decision variables to confirm that his computational representation was robust to alternative initial conditions. Davis and colleagues (2007) used two alternative operationalizations of their

\footnotetext{
${ }^{6}$ Both verification and experimentation involve running the simulation, and thus making several specific decisions about those runs. One is the number of time steps. The appropriate number depends on researcher objectives (e.g., observing the process unfold, assessing the time to reach on optimal point, and examining steady-state processes), and so researchers should justify their choice in light of their objectives. A second decision is the number of runs per set of specific values of independent constructs. This is roughly analogous to sample size in hypothesis-testing researchspecifically, the sample size in a cell of an ANOVA laboratory study. Here the decision depends on statistical power. More runs raise the statistical power, so the choice depends on the power necessary to perform adequate statistical analysis (i.e., creating confidence intervals for dependent variable values). The third is the number of sets, roughly analogous to the number of different conditions in a laboratory study-that is, the number of cells in an ANOVA laboratory study. However, unlike laboratory researchers, simulation researchers are able to make many runs, and so often only report those that are the most significant vis-à-vis conveying their results. Researchers should also justify these latter decisions in light of their research. We refer interested readers to texts on simulation (e.g., Law \& Kelton, 1991) for more information.

${ }^{7}$ Sensitivity analysis is a widely used term within simulation with several meanings. We use more precise language to distinguish three kinds of analysis that are often termed sensitivity analysis: verification of propositions of simple theory, robustness checks of the computational representation (roughly analogous to the meaning of robustness using empirical methods), and experimentation to create new theory.
}

organizational structure construct to verify that their simulation results were not dependent upon a specific representation of their central construct. Researchers should also use other techniques to verify that their software coding is correct, such as tracking variables at intermediate steps in simulation and running the simulation with extreme values of constructs, and those techniques specific to particular simulation approaches (e.g., pulse tests in system dynamics). These tests often have no theoretical implications but, rather, are a means of verifying the accuracy of the software code.

When researchers find a mismatch between the propositions of their simple theory and the simulation results, it is often due to software coding errors that are subsequently fixed. But, occasionally, the mismatch reveals shortcomings in the theoretical logic. In these situations, researchers often have an opportunity to develop fresh theoretical insights. For example, Davis and colleagues (2007) unexpectedly observed that the anticipated inverted U-shaped relationship between the amount of organizational structure and performance was asymmetric (i.e., steep on one side and skewed on the other). This led the authors to alter their simple theory to account for this skew. While Davis and colleagues (2007) modestly improved their initial theory, Sastry (1997) made a significant improvement. In her attempt to verify her computational representation of punctuated equilibrium theory, she found shortcomings in the theoretical logic. Sastry returned to the original theory and discovered that Tushman and Romanelli (1985) had failed to account for some aspects of reorientation. This unexpected logical flaw led Sastry to reformulate the theory by adding assumptions and a negative feedback process.

Overall, the key point of verification is to ensure that the computational representation accurately represents the underlying theoretical logic. Thus, given that the researcher attempts to encode the theoretical logic in the software, the simulation results should replicate the simple theory, bolster internal validity, and thereby increase confidence in the results of the simulation.

\section{Experiment to Build Novel Theory}

Experimentation is at the heart of the value of simulation methods for developing theory. 
While verification of the computational representation is necessary and useful for demonstrating the accuracy of the computational representation, establishing internal validity, and enhancing reader confidence, it involves confirmation of theory that is already known. In contrast, effective experimentation builds new theory by revealing fresh theoretical relationships and novel theoretical logic. Moreover, experimentation is a particular strength of simulation methods. Empirical experimentation is constrained by data limitations, and formal modeling experimentation is constrained by mathematical tractability. In contrast, simulation methods enable experimentation across a wide range of conditions, simply by changing the software code (Bruderer \& Singh, 1996; Zott, 2003).

There are several approaches to effective experimentation. A common one is varying the value of constructs that were held constant in the initial simple theory. This approach is particularly useful for uncovering moderating and interaction relationships, new main effects, and intervening constructs. Typically, researchers experiment with $\alpha$ wide range of values of $\alpha$ previously fixed construct in order to fully explore the effects of the construct on outcomes, but they then only report the most intriguing results. For example, after verifying their initial proposition that experiential learning and cognition would lead to a higher performance than experiential learning alone, Gavetti and Levinthal (2000) varied the coupling among policy elements that was previously held constant. This enabled the authors to investigate how coupling moderated the relationship between cognition and performance and to extend their simple theory with this interaction effect. Similarly, Rudolph and Repenning (2002) examined the effects of minor interruptions on the emergence of major organizational catastrophes. After verifying the anticipated tipping points, the authors experimented by varying the previously constant variance in the interruption rate. This enabled the authors to extend their original simple theory to include the interaction effects of interruption variance on performance.

A second approach to experimentation is unpacking key theoretical constructs. By unpacking, we mean breaking a single construct into constituent component constructs. Unpacking a construct is particularly useful when the origi- nal construct is imprecise, abstract, or multidimensional such that the different dimensions may have distinct effects. Experiments then focus on uncovering these possible effects. For example, after verifying their simple theory, Davis and colleagues (2007) unpacked their market dynamism construct into four granular constructs (i.e., velocity, complexity, ambiguity, and unpredictability) that captured distinct dimensions of market dynamism. They then experimented with each construct by running the simulation holding three constructs constant and varying the fourth. This enabled the authors to extend their theory to the performance implications of different kinds of market dynamism and to isolate the specific implications of each construct for their theory.

A third approach to experimentation is varying assumptions. This approach is particularly useful when fundamentally different processes may reasonably exist. Experiments focus on revealing their possible distinct effects. For example, Rivkin (2000) verified his theory relating the speed with which executives find high-performing strategies to the coupling among elements of strategy. In doing so, he assumed an "incremental" search process in which executives change their current strategy only if altering specific decisions within that strategy leads to increased performance. He then experimented with two alternative search processes: "followthe-leader" and "hybrid." These experiments enabled him to elaborate his original theory to include the implications of alternative search processes.

A fourth approach to experimentation is adding new features to the computational representation. By adding this complexity in successive computational representations, researchers can build theoretical understanding of the phenomenon in a structured way that enhances the understanding of both researchers and readers. Additional complexity (e.g., processes and constructs) is particularly useful when researchers want to explore the interaction of multiple processes that are well-known alone but not in combination and, more broadly, when greater realism is desired. For example, Repenning's (2002) simple theory related persistence of managerial commitment to the success of new innovations. After verifying this theory with a single organizational group, he experimented by adding an additional feature (i.e., second organiza- 
tional group) that made the simulation more complex but also more realistic. In revealing that a second organizational group is unlikely to be successful in adopting an innovation, Repenning extended his simple theory to include multiple groups, thereby enhancing its theoretical relevance for real organizations.

Several criteria should shape experimentation design. The most important criterion is theoretical contribution. Understanding where theoretical contributions are likely to be usually stems from knowledge of the literature. Although serendipitous discoveries can occur, knowing the literature often enables the researcher to know where theoretical discrepancies are and so where to experiment to improve the likelihood of intriguing theoretical insights. Such insights are the reason d'être of the research. A related criterion for experimentation design is realism. As noted earlier, it is often effective to begin with a simple computational representation in order to build reader intuition and confidence in the simulation. Experimentation can then add realism that enhances the generalizability of the resulting theory.

Experimentation is closely associated with building theory using "disciplined imagination" (Weick, 1989). That is, researchers using simulation can readily engage in an evolutionary process of speculative experiments to create alternative versions of theory (imagination) and then select the best among them (discipline). Although researchers can engage in disciplined imagination using other methods, such as systematic thought experiments, these methods often fail when the theory involves intertwined and longitudinal processes, timing effects, and nonlinearities that are the province of simulation. In effect, the simple theory of a simulation becomes a platform for elaborating and extending theory through creative and systematic experimentation (Weick, 1989). The result may be fundamental (i.e., widely applicable and nonobvious) theory (Lave \& March, 1975).

Overall, experimentation is at the heart of the value of using simulation methods for theory development. While verification confirms existing theory and bolsters internal validity, experimentation adds the creative and even surprising theoretical contributions that build new theory. Sometimes this new theory is an incremental advance. But sometimes this theory is a fundamental improvement in which frame- breaking insights generate qualitatively better theory.

\section{Validate with Empirical Data}

A final step in theory development using simulation methods is validation. Validation involves comparison of simulation results with empirical data. If the results of the simulation match the empirical evidence, then the simulation is validated for that empirical context. This strengthens the external validity of the theorythat is, generalizability and predictability of the theory (Campbell \& Stanley, 1966).

There is, however, some debate over the value of validation. For example, some theorists argue that the central task of theory development is creating interesting theory, and so they diminish the importance of validation (e.g., Van Maanen, 1995; Weick, 1989). Others disagree. Our view is contingent-that is, the importance of validation should depend on the source of the simple theory that is the basis of the simulation. If this theory is based primarily on empirical evidence (e.g., field-based case studies and empirically grounded processes), then validation is less important, because the theory already has some external validity. In contrast, if the theory is based primarily on nonempirical argument (e.g., formal analytic modeling) or on evidence from distant scientific disciplines (e.g., physics), then validation is more important.

There are several approaches to effective validation. One is to compare the results of the simulation to statistical results derived from large-scale empirical data. This approach enables a broad-brush validation of the simulation results (Adner \& Levinthal, 2001). A standard technique in economics, for instance, is to use theories developed with simulation to "predict" the results of some well-known data set. For example, Nelson and Winter (1982) created a simulation of their theory of evolutionary economic change and then used that simulation to reproduce historical productivity data. Another approach is to compare the simulation results and theoretical logic with case study data. This approach seeks to demonstrate that the simulation is consistent with the specific details of one or a few examples. This enables granular validation. For example, Sterman and colleagues (1997) used interview data from one organization to show that their theory of organizational 
change was plausible in at least this one organization. The choice between these two approaches usually depends on data availability.

\section{DISCUSSION}

While simulation is an increasingly significant methodological approach in the organizations and strategy literature (e.g., Lant \& Mezias, 1990; Rivkin \& Siggelkow, 2003; Repenning, 2002; Zott, 2003), its link to theory development remains unclear and even controversial. Our purpose here has been to clarify when and how to use simulation methods to develop theory.

Our first contribution was a roadmap for conducting effective theory development using simulation. Like all effective research, developing theory from simulation methods depends on beginning with an intriguing research question that relates to fundamental theoretical issues. Simulation is especially effective when that research question relates to competing tensions (e.g., long versus short run, structure versus chaos) and intertwined processes (e.g., inertia and change, competition and legitimation) that are especially well-addressed by simulation. The central activity is developing an accurate computational representation of simple (i.e., undeveloped) theory through appropriate selection of a simulation approach (e.g., genetic algorithm versus stochastic processes), construct operationalization, and algorithmic representation. The benefits of simulation emerge in verifying the computational representation, which strengthens the internal validity of the simple theory, and, more significant, in creatively experimenting to produce novel theoretical insights. Indeed, creative experimentation is at the heart of the value of simulation methods for theory development.

Our second contribution was positioning simulation methods within the broad context of theoretical development in the organizations and strategy literature. Simulation is particularly useful for developing theory in the "sweet spot" between theory creating using such methods as multiple case inductive research (Eisenhardt, 1989) and formal modeling (Freese, 1980) and theory testing using empirical evidence and multivariate statistical techniques (Lattin, 2003; Pfeffer, 1993). On the one hand, theory-creating methods can reveal simple theory but are limited in their ability to elaborate that theory. The inductive case method is constrained by limited data, and formal modeling is constrained by mathematical tractability. Simulation can mitigate these weaknesses by exploring, elaborating, and extending simple theory that is produced by these theory-creating methods. On the other hand, as Sutton and Staw (1995) argue, many theory-testing studies lack conceptual precision and logical theoretical argument. Simulation can mitigate these weaknesses in internal validity by tightening the rigor of the underlying theoretical logic, sharpening constructs, and elaborating theoretical propositions prior to empirical test.

\section{Strengths and Weaknesses}

These observations suggest several important strengths for developing theory with simulation. One is internal validity (Cook \& Campbell, 1979). The computational rigor of simulation forces precise specification of constructs, assumptions, and theoretical logic that creates strong internal validity. This emphasis on internal validity is particularly valuable because it addresses $a$ common weakness of empirical research: often poor theoretical logic regarding "why" propositions might be true (Sutton \& Staw, 1995; Whetten, 1989). This emphasis also mitigates another common weakness of empirical research: weak specification of boundary conditions. By requiring precise specification of assumptions, simulation typically bounds the scope of the theory and so clarifies boundary conditions. Thus, while other methods emphasize constructs and propositions, simulation puts their underlying theoretical logic and assumptions center stage.

Another strength is experimentation. Simulation creates a computational laboratory in which researchers can systematically experiment (e.g., unpack constructs, relax assumptions, vary construct values, add new features) in a controlled setting to produce new theoretical insights. This experimentation is particularly valuable when the theory seeks to explain longitudinal and processual phenomena that are challenging to study using empirical methods because of their time and data demands. Simulation is also well-suited to theory development related to nonlinear phenomena, such as tipping points, feedback loops, thresholds and catastrophes, and asymmetries. These are difficult to uncover using inductive case methods 
and to examine using standard statistical techniques. Yet, significantly, these phenomena are becoming central as theory development moves from cross-sectional and equilibrium perspectives to longitudinal and dynamic ones.

Yet, like all methods, theory development using simulation has weaknesses. A primary one is external validity. Simulation eliminates complexity in order to focus on the core aspects of phenomena and so uses computational representations that are often stark, such as representing an organization by a 0/1 bit string (Bruderer \& Singh, 1996), or making clearly false assumptions, such as no disadvantages to being a second mover (Rivkin, 2000). The result can be an overly simplistic and distant model that fails to capture critical aspects of reality.

\section{Toward Better Theory Development Using Simulation Research}

Like all research, theory development using simulation methods should be evaluated according to two fundamental criteria: theoretical contribution and strength of method. Theoretical contribution is partially determined by the quality of the research question and its related grounding in the literature. That is, the research question should center on a significant issue within the related literature. In contrast, research with no grounding in the relevant literature often has a research question that does not address a useful theoretical gap, or it has theoretical constructs and theory that do not fit with their conceptualization and terminology within the literature. This lack of grounding can further lead to weak integration of the simulation results with the literature. While awareness of and at least some grounding in the extant literature seem obvious, our experience indicates that simulation researchers are more likely to misunderstand their research context (i.e., choose poor research questions, fail to understand and use well-developed concepts) than others, or to simply pass over the contributions of others working with different methods. Yet without situating the research question and theory in the current literature and then relating results to that literature, it is difficult to have a theoretical contribution. Thus, the reader should ask whether the research is situated within the relevant research literature and addresses a substantive research question.
Theoretical contribution is also determined by the quality of the experimentation. As noted earlier, experimentation is a key strength of simulation and the primary source of theoretical insight. That is, systematic experimentation focused on unexplored theoretical constructs (e.g., varying construct values, unpacking constructs into more precise constructs), major assumptions (e.g., relaxing them, varying them), and important elaborations (e.g., adding new features) is integral to theoretical contribution. Therefore, when evaluating theory development using simulation, the reader should focus on the experimentation to assess whether and to what extent theoretical contribution has been made.

Simulation authors should likewise distinguish between the verification of the simple theory that confirms the computational representation and the internal validity, and the theoretical insights that emerge from systematic experimentation (or occasionally from failed verification) that creatively elaborate and extend the theory. Although this may seem obvious, simulation researchers have a tendency to communicate their findings as if simply simulation of a phenomenon per se is a theoretical contribution. That is, they confuse building a simulation with theoretical contribution. Some also stop at verification (e.g., various robustness checks), rather than continuing to genuine experimentation. But research that only verifies known theory or jumbles verification and experimentation typically fails to create theoretical contribution. Indeed, like all research, the theoretical contribution of simulation research is independent of method and relates to the addition of new theoretical insight. Thus, the reader should ask whether the results constitute a theoretical contribution.

The second criterion is the strength of method. In the context of the roadmap outlined earlier, a high-quality method includes justification for using simulation for the research question at hand and using a simulation approach (e.g., cellular automata, stochastic processes) that fits the research. For example, as is common practice in empirical research, simulation researchers should clearly justify the simulation approach (as one would justify a statistical approach), define constructs, and indicate the computational measures (as one would describe empirical measures). The methods section of 
other types of research provides a useful template for conveying this information.

In addition, high-quality simulation methods should have an accurate computational representation of the theoretical logic that is conveyed to the reader in a way that carefully builds understanding of assumptions and the logical flow of the simulation. Given the opacity of computer coding, this puts a premium on the effective presentation of the theoretical logic. In addition to logical argument (roughly analogous to the theoretical development of hypotheses in empirical research), pictures and flowcharts are helpful in this regard (see Rudolph \& Repenning, 2002, and Zott, 2003, for exemplars). High-quality simulation methods also include explicit verification of the computational representation that confirms the accuracy and internal validity of the computational representation and builds reader confidence in the simulation. It is helpful to explicitly state the propositions of the simple theoretical ideas that form the basis of the simulation and then to verify them clearly by running the simulation. In contrast, when the computational representation is poor, poorly described, or unverified, the simulation results are unreliable and/or not believed.

Finally, a high-quality method involves the appropriate statistical design of the verification and experimentation simulation runs. This design should include an appropriate number of time steps in each simulation run and number of simulation runs per experiment (related to the statistical power). As in empirical research, high-quality simulation methods also include statistical confidence intervals (Law \& Kelton, 1991). In contrast, when research does not justify the basic statistical properties of the simulation (e.g., number of time steps, number of runs per experiment) or provide basic statistical analysis (i.e., confidence intervals), confidence in the statistical results is compromised.

Overall, readers should expect that highquality theory development using simulation methods meets the usual standards of strong theory, such as parsimony, internal validity, accuracy, and interest (Davis, 1971; Eisenhardt, 1989; Pfeffer, 1982; Priem \& Butler, 2001). Or, more simply, the result should explain, predict, and delight (Weick, 1989). Given the starting point of simple theory, the result of effective simulation can be fundamental theory that is parsimonious, internally consistent, and applicable to a wide range of situations (Pfeffer, 1982).

\section{CONCLUSION}

We began by observing that while simulation is a significant method for theory development, its usefulness is unclear and even controversial. Our purpose was to clarify how and when to use simulation methods for theory development. We provide two contributions. One is a roadmap for developing theory through simulation (Table 1), including the pivotal role of experimentation in creating theoretical contribution. The second is positioning simulation methods in the "sweet spot" between theory creating using inductive case methods and formal modeling, and theory testing using multivariate statistical techniques. We conclude by observing that simulation is likely to become an increasingly prominent method of theory development. As organizations and strategy scholars move to an emphasis on theory explaining dynamic and longitudinal phenomena, simulation methods will be a natural choice.

\section{REFERENCES}

Abelson, H., Sussman, G. J., \& Sussman, J. 1996. Structure and interpretation of computer programs. Cambridge, MA: MIT Press.

Adner, R. 2002. When are technologies disruptive? A demand-based view of the emergence of competition. Strategic Management Journal, 23: 667-688.

Adner, R., \& Levinthal, D. 2001. Demand heterogeneity and technology evolution: Implications for product and process innovation. Management Science, 47: 611-628.

Aldrich, H. 1999. Organizations evolving. Thousand Oaks, CA: Sage.

Andreoni, J., \& Miller, J. 1995. Auctions with artificial adaptive agents. Games and Economic Behavior, 10: 39-64.

Arifovic, J., Bullard, J., \& Duffy, J. 1997. The transition from stagnation to growth: An adaptive learning approach. Journal of Economic Growth, 2: 185-209.

Bruderer, E., \& Singh, J. S. 1996. Organizational evolution, learning, and selection: A genetic-algorithm-based model. Academy of Management Journal, 39: 1322-1349.

Bullard, J., \& Duffy, J. 2001. Learning and excess volatility. Macroeconomic Dynamics, 5(2): 272-302.

Campbell, D. T., \& Fiske, D. W. 1959. Convergent and discriminant validation by the multitrade-multimethod matrix. Psychological Bulletin, 56: 81-105.

Campbell, D. T., \& Stanley, J. C. 1966. Experimental and 
quasi-experimental designs for research. Chicago: Rand McNally.

Carley, K. M. 2001. Computational approaches to sociological theorizing. In J. Turner (Ed.), Handbook of sociological theory: 69-84. New York: Kluwer Academic/Plenum.

Carroll, G., \& Harrison, J. R. 1998. Organizational demography and culture: Insights from a formal model and simulation. Administrative Science Quarterly, 43: 637-667.

Chattoe, E. 1998. Just how (un)realistic are evolutionary algorithms as representations of social processes? Journal of Artificial Social Science Simulation, 1(3): 2.1-2.36.

Cohen, M. D., March, J., \& Olsen, J. P. 1972. A garbage can model of organizational choice. Administrative Science Quarterly, 17: 1-25.

Cook, T. D., \& Campbell, D. T. 1979. Quasi-experimentation: Design and analysis issues for field settings. Boston: Houghton Mifflin.

Davis, J., Eisenhardt, K., \& Bingham, C. 2007. Complexity theory, market dynamism, and the strategy of simple rules. Working paper, Stanford Technology Ventures Program, Stanford University, Stanford, CA.

Davis, M. S. 1971. That's interesting! Towards a phenomenology of sociology and a sociology of phenomenology. Philosophy of Social Science, 1: 309-344.

Dooley, K. 2002. Simulation research methods. In J. A. C. Baum (Ed.), Companion to organizations: 829-848. Oxford: Blackwell.

Dubin, R. 1976. Theory building in applied areas. In M. Dunnette (Ed.), Handbook of industrial and organizational psychology: 17-40. Chicago: Rand McNally.

Eisenhardt, K. M. 1989. Building theories from case study research. Academy of Management Review, 14: 532-550.

Fichman, M. 1999. Variance explained: Why size doesn't (always) matter. Research in Organizational Behavior, 21: 295-331.

Fine, G. A., \& Elsbach, K. D. 2000. Ethnography and experiment in social psychological theory building. Journal of Experimental Social Psychology, 36: 51-76.

Forrester, J. 1961. Industrial dynamics. Cambridge, MA: MIT Press.

Freese, L. 1980. Formal theorizing. Annual Review of Sociology, 6: 187-212.

Gallager, R. 1996. Discrete stochastic processes. Boston: Kluwer Academic.

Gavetti, G., \& Levinthal, D. 2000. Looking forward and looking backward: Cognitive and experiential search. Administrative Science Quarterly, 45: 113-137.

Goldberg, D. E. 1989. Genetic algorithms: In search of optimization and machine learning. Reading, MA: AddisonWesley.

Hannan, M. T., \& Freeman, J. 1989. Organizational ecology. Cambridge, MA: Harvard University Press.

Harrison, J. R., \& Carroll, G. R. 1991. Keeping the faith: A model of cultural transmission in formal organizations. Administrative Science Quarterly, 36: 552-582.
Holland, J. H. 1975. Adaptation in natural and artificial systems. Ann Arbor: University of Michigan Press.

Kauffman, S. 1989. Adaptation on rugged fitness landscapes. In E. Stein (Ed.), Lectures in the science of complexity, vol. 1. Reading, MA: Addison-Wesley.

Kauffman, S. 1993. The origins of order. New York: Oxford University Press.

Kreps, D. M. 1990. Corporate culture and economic theory. In J. E. Alt \& K. A. Shepsle (Eds.), Perspectives on positive political economy: 90-143. Cambridge \& New York: Cambridge University Press.

Langton, C. G. 1984. Self-reproduction in cellular automata. Physica, 10D: 134-144.

Lant, T., \& Mezias, S. 1990. Managing discontinuous change: A simulation study of organizational learning and entrepreneurship. Strategic Management Journal, 11: 147179.

Lant, T., \& Mezias, S. 1992. An organizational learning model of convergence and reorientation. Organization Science, 3: 47-71.

Lattin, J. 2003. Analyzing multivariate data. Toronto: Brooks/ Cole, Thomson Learning.

Lave, C., \& March, J. G. 1975. An introduction to models in the social sciences. New York: Harper \& Row.

Law, A. M., \& Kelton, D. W. 1991. Simulation modeling and analysis (2nd ed.). New York: McGraw-Hill.

Lee, T., Mitchell, T., Sablynski, C. 1999. Qualitative research in organizational and vocational psychology. Journal of Vocational Behavior, 55: 161-187.

Levinthal, D. 1997. Adaptation on rugged landscapes. Management Science, 43: 934-950.

Lomi, A., \& Larsen, E. 1996. Interacting locally and evolving globally: A computational approach to the dynamics of organizational populations. Academy of Management Journal, 39: 1287-1321.

March, J. G. 1991. Exploration and exploitation in organizational learning. Organization Science, 2: 71-87.

Nelson, R. R., \& Winter, S. G. 1982. An evolutionary theory of economic change. Cambridge, MA: Belknap Press of Harvard University Press.

Pfeffer, J. 1982. Organizations and organization theory. Boston: Pitman.

Pfeffer, J. 1993. Barriers to the advance of organizational science: Paradigm development as a dependent variable. Academy of Management Review, 18: 599-620.

Priem, R. L., \& Butler, J. E. 2001. Is the resource-based "view" a useful perspective for strategic management research? Academy of Management Review, 26: 22-41.

Repenning, N. 2002. A simulation-based approach to understanding the dynamics of innovation implementation. Organization Science, 13: 109-127.

Repenning, N. 2003. Selling system dynamics to (other) social scientists. System Dynamics Review, 19: 303-327.

Rivkin, J. W. 2000. Imitation of complex strategies. Management Science, 46: 824-844. 
Rivkin, J. W. 2001. Reproducing knowledge: Replication without imitation at moderate complexity. Organization Science, 12: 274-293.

Rivkin, J. W. \& Siggelkow, N. 2003. Balancing search and stability: Interdependencies among elements of organizational design. Management Science, 49: 290-31l.

Rosenthal, R., \& Rosenow, R. L. 1991. Essentials of behavioral research: Methods and data analysis (2nd ed.). New York: McGraw-Hill.

Rudolph, J., \& Repenning, N. 2002. Disaster dynamics: Understanding the role of quantity in organizational collapse. Administrative Science Quarterly, 47: 1-30.

Sastry, M. A. 1997. Problems and paradoxes in a model of punctuated organizational change. Administrative Science Quarterly, 42: 237-275.

Schelling, T. 1971. Dynamic models of segregation. Journal of Mathematical Sociology, 1: 143-186.

Sterman, J. 2000. Business dynamics: Systems thinking and modeling for a complex world. New York: Irwin McGraw-Hill.

Sterman, J., Repenning, N., \& Kofman, F. 1997. Unanticipated side effects of successful quality programs: Exploring a paradox of organizational improvement. Management Science, 43: 503-521.

Stinchcombe, A. 1968. Constructing social theories. Chicago: University of Chicago Press.

Sutton, R. I., \& Staw, B. M. 1995. What theory is not. Administrative Science Quarterly, 40: 371-384.
Tushman, M., \& Romanelli, E. 1985. Organizational evolution: A metamorphosis model of convergence and reorientation. Research in Organizational Behavior, 7: 171-222.

Van Maanen, J. 1995. Style as theory. Organization Science, 6: 133-143.

Weick, K. E. 1989. Theory construction as disciplined imagination. Academy of Management Review, 14: 516-531.

Weick, K. E. 1993. The vulnerable system: An analysis of the Tenerife air disaster. In K. H. Roberts (Ed.), New challenges to understanding organizations: 173-198. New York: Macmillan.

Whetten, D. 1989. What constitutes a theoretical contribution? Academy of Management Review, 14: 490-495.

Wolfram, S. 2002. A new kind of science. Champaign, IL: Wolfram Media.

Wright, S. 1931. Evolution in Mendelian populations. Genetics, 16: 97-159.

Yerkes, R. M., \& Dodson, J. D. 1908. The relation of strength of stimulus to rapidity of habit formation. Journal of Comparative Neurological Psychology, 18: 459-482.

Zott, C. 2002. When adaptation fails: An agent-based explanation of inefficient bargaining under private information. Journal of Conflict Resolution, 46: 727-753.

Zott, C. 2003. Dynamic capabilities and the emergence of intra-industry differential firm performance: Insights from a simulation study. Strategic Management Journal, 24: 97-125.

Jason P. Davis (jpdavis@stanford.edu) is a doctoral candidate in management science and engineering, Stanford University, where he received his M.A. in sociology. His current research interests include competitive strategy, organizational structure, and collaborative technology innovation in highly dynamic environments. He uses a combination of inductive, multicase, and simulation methods.

Kathleen M. Eisenhardt (kme@stanford.edu) is the Stanford W. Ascherman M.D. Professor at Stanford University and codirector of the Stanford Technology Ventures Program. She received her Ph.D. from Stanford University. Her current research interests include competitive interaction and strategic approaches to power by enterpreneurial firms, multibusiness organization, and strategy as simple rules.

Christopher B. Bingham (cbingham@umd.edu) is assistant professor of strategy and organization at the Robert H. Smith School of Business, University of Maryland. He received his Ph.D. from Stanford University. His current research interests revolve around organizational learning and change, dynamic capabilities, and strategy in unpredictable environments. 
Copyright of Academy of Management Review is the property of Academy of Management and its content may not be copied or emailed to multiple sites or posted to a listserv without the copyright holder's express written permission. However, users may print, download, or email articles for individual use. 